\title{
Effects of macroalgae loss in an Antarctic marine food web: applying extinction thresholds to food web studies
}

\author{
Georgina Cordone ${ }^{\text {Corresp., }}{ }^{1}$, Tomás I. Marina ${ }^{2,3,4}$, Vanesa Salinas ${ }^{2}$, Santiago R. Doyle ${ }^{2,3}$, Leonardo A. Saravia ${ }^{2,3}$ \\ , Fernando R. Momo ${ }^{2,3}$ \\ ${ }^{1}$ Centro Nacional Patagónico (CCT CONICET-CENPAT), Centro Para el Estudio de Sistemas Marinos (CESIMAR), Puerto Madryn, Chubut, Argentina \\ 2 Universidad Nacional de General Sarmiento, Instituto de Ciencias (ICI), Los Polvorines, Buenos Aires, Argentina \\ 3 Universidad Nacional de Luján, Instituto de Ecología y Desarrollo Sustentable (INEDES), Luján, Buenos Aires, Argentina \\ 4 Consejo Nacional de Investigaciones Científicas y Técnicas (CONICET), Centro Austral de Investigaciones Científicas (CADIC), Ushuaia, Tierra del Fuego, \\ Argentina
}

Corresponding Author: Georgina Cordone

Email address: gcordone@cenpat-conicet.gob.ar

Antarctica is seriously affected by climate change, particularly at the Western Antarctic Peninsula (WAP) where a rapid regional warming is observed. Potter Cove is a WAP fjord at Shetland Islands that constitutes a biodiversity hotspot where over the last years, Potter Cove annual air temperatures averages increased by $0.66^{\circ} \mathrm{C}$, coastal glaciers declined, and suspended particulate matter increased due to ice melting. Macroalgae are the main energy source for all consumers and detritivores of Potter Cove. Some effects of climate change favor pioneer macroalgae species that exploit new ice-free areas and can also decline rates of photosynthesis and intensify competition between species due to the increase of suspended particulate matter. In this study, we evaluated possible consequences of climate change at Potter Cove food web by simulating the extinction of macroalgae and detritus using a topological approach with thresholds of extinction. Thresholds represent the minimum number of incoming links necessary for species' survival. When we simulated the extinctions of macroalgae species at random, a threshold of extinction beyond $50 \%$ was necessary to obtain a significant number of secondary extinctions, while with a $75 \%$ threshold a real collapse of the food web occurred. Our results indicate that Potter Cove food web is relative robust to macroalgae extinction. This is dramatically different from what has been found in other food webs, where the reduction of $10 \%$ in prey intake caused a disproportionate increase of secondary extinctions. Robustness of the Potter Cove food web was mediated by omnivory and redundancy, which had an important relevance in this food web. When we eliminated larger-biomass species more secondary extinctions occurred, a similar response was observed when more connected species were deleted, yet there was no correlation between species of largerbiomass and high-degree. This similarity could be explained because both criteria involved key species that produced an emerging effect on the food web. In this way, large-biomass 
and high-degree species could be acting as source for species with few trophic interactions or low redundancy. Based on this work, we expect Potter Cove food web to be robust to changes in macroalgae species caused by climate change until a high threshold of stress is reached, and then negative effects are expected to spread through the entire food web leading to its collapse. 


\section{Effects of macroalgae loss in an Antarctic marine food web: 2 applying extinction thresholds to food web studies}

3 Georgina Cordone 1, Tomás I. Marina 2, 3,4, Vanesa Salinas 2, Santiago R. Doyle 2,3, Leonardo A. Saravia 2,3,

4 Fernando R. Momo 2,3

$5{ }^{1}$ Centro Nacional Patagónico (CCT CONICET-CENPAT), Centro Para el Estudio de Sistemas Marinos

6 (CESIMAR), Puerto Madryn, Chubut, Argentina

72 Universidad Nacional de General Sarmiento, Instituto de Ciencias (ICI), Los Polvorines, Buenos Aires,

8 Argentina

9 3 Universidad Nacional de Luján, Instituto de Ecología y Desarrollo Sustentable (INEDES), Luján, Buenos

10 Aires, Argentina

$11{ }^{4}$ Consejo Nacional de Investigaciones Científicas y Técnicas (CONICET), Centro Austral de

12 Investigaciones Científicas (CADIC), Ushuaia, Tierra del Fuego, Argentina

13 Corresponding Author:

14 Georgina Cordone ${ }^{1}$

15 Bv. Almte Brown 2915, Puerto Madryn, Chubut, 9120, Argentina

16 Email address: gcordone@cenpat-conicet.gob.ar

17 


\section{Abstract}

Antarctica is seriously affected by climate change, particularly at the Western Antarctic Peninsula (WAP) where a rapid regional warming is observed. Potter Cove is a WAP fjord at Shetland Islands that constitutes a biodiversity hotspot where over the last years, Potter Cove annual air temperatures averages increased by $0.66^{\circ} \mathrm{C}$, coastal glaciers declined, and suspended particulate matter increased due to ice melting. Macroalgae are the main energy source for all consumers and detritivores of Potter Cove. Some effects of climate change favor pioneer macroalgae species that exploit new ice-free areas and can also decline rates of photosynthesis and intensify competition between species due to the increase of suspended particulate matter. In this study, we evaluated possible consequences of climate change at Potter Cove food web by simulating the extinction of macroalgae and detritus using a topological approach with thresholds of extinction. Thresholds represent the minimum number of incoming links necessary for species' survival. When we simulated the extinctions of macroalgae species at random, a threshold of extinction beyond $50 \%$ was necessary to obtain a significant number of secondary extinctions, while with a $75 \%$ threshold a real collapse of the food web occurred. Our results indicate that Potter Cove food web is relatively robust to macroalgae extinction. This is dramatically different from what has been found in other food webs, where the reduction of $10 \%$ in prey intake caused a disproportionate increase of secondary extinctions. Robustness of the Potter Cove food web was mediated by omnivory and redundancy, which had an important relevance in this food web. When we eliminated larger-biomass species more secondary extinctions occurred, a similar response was observed when more connected species were deleted, yet there was no correlation between species of larger-biomass and high-degree. This similarity could be explained because both criteria involved key species that produced an emerging effect on the food web. In this way, large-biomass and high-degree species could be acting as source for species with few trophic interactions or low redundancy. Based on this work, we expect Potter Cove food web to be robust to changes in macroalgae species caused by climate change until a high threshold of stress is reached, and then negative effects are expected to spread through the entire food web leading to its collapse.

\section{Introduction}

Western Antarctic Peninsula (WAP) is the region of Antarctica most affected by climate change, with a regional warming rate that doubles what is observed in other Antarctic regions (McClintock, Ducklow \& Fraser, 2008; Turner et al., 2009; Bromwich et al., 2013; Nicolas \& Bromwich, 2014). One particular example of environmental changes in WAP was observed at Potter Cove (Fig. 1), a hotspot of biodiversity, where over the last years the average winter air temperatures increased by $0.66^{\circ} \mathrm{C}$, coastal glaciers declined and suspended particulate matter increased due to ice melting (Schloss et al., 2012; Bers et al., 2013; Ducklow et al., 2013; Quartino et al., 2013; Grange \& Smith, 2013; Lagger et al., 2017). These changes produce a variety of effects on the organisms of the cove; pioneer macroalgae species are favored by the increase of rocky bottom areas due to glaciers retreat (Quartino et al., 2013), whereas increased 
suspended particulate matter affects rates of photosynthesis and intensity of competition between species (Quartino et al., 2013; Deregibus et al., 2016). Moreover, a long-term succession study showed that sites with higher levels of stress and disturbance caused by glacial influence presented lower number of macroalgal taxa and a tendency to decrease diversity over time (Campana et al., 2018). In recent years, environmental changes have triggered modifications at the benthic community of Potter Cove (Pasotti et al., 2015; Sahade et al., 2015). The community structure changed from an assemblage dominated by filter feeders squirts to a mixed assemblage, and this alteration can be explained by organism sensitivity to increased sedimentation (Sahade et al., 2015). A descriptive analysis of the Potter Cove food web has suggested fragility to species loss and susceptibility to propagation of trophic cascade effects based on topology parameters as connectance $(C)$ or link density $(L D)$ (Marina et al., 2018). However, alternative food sources could contribute to food web robustness (Marina et al., 2018).

About forty species of macroalgae have been reported at Potter Cove (Quartino \& Boraso de Zaixso, 2008a), a significant fraction of the approximately 130 registered for Antarctica as a whole. In Potter Cove, macroalgae constitute a direct pathway of energy and matter into organisms that feed on them, and also indirectly, through species that feed on macroalgae detritus (Quartino, Boraso de Zaixso \& Momo 2008b). Macroalgae are not only important as primary producers that supply significant amounts of fixed carbon to marine ecosystems, but as substrates for organisms that inevitably provide a large fraction of the secondary production to the benthos (Gómez et al., 2009). Considering this, we can reaffirm the words of Neushul (1965) that macroalgae are the energetic base of Potter Cove food webs.

Since the macroalgal community plays a fundamental role in Potter Cove food web, it might affect ecosystem dynamics and stability through propagation of direct and indirect effects. Changes in species abundance or presence can indeed alter the whole community structure (e.g. Dulvy et al., 2000; Jackson et al., 2001; Ellison et al., 2005; Sorte et al., 2017). Moreover, the loss of species can lead to a cascade of secondary extinctions that propagate through the community (Ebenman, Law \& Borrvall 2004; Sanders, Sutter \& Veen, 2013; Donohue et al., 2017; Witman, Smith \& Novak, 2017). Food webs are considered an excellent tool to explore possible effects of global change and biodiversity loss on communities and ecosystems, since trophic interactions are crucial for the survival of both resource and consumer species (Ings et al., 2009; Bascompte, 2009; Hastings, McCann \& de Ruiter, 2016). The vulnerability of food webs to adverse effects can be estimated from the topology of the network (de Santana et al., 2013). Several authors have studied the effects of species extinctions in food webs (Sóle \& Montoya, 2001; Dunne, Williams \& Martinez, 2002; Memmott, Waser \& Price, 2004; Allesina et al., 2006; Curtsdotter et al., 2011; Eklöf, Tang \& Allesina, 2013; Bellingeri et al., 2013). Borvall et al. (2000) studied the effect of omnivory and redundancy in model food webs, and found that both lessen the risk of cascading extinctions following primary loss of species. Additionally, Montoya \& Solé (2002) demonstrated that food webs are vulnerable to the elimination of the most connected species. Moreover, it has been observed that extinctions and invasions can alter costal marine food webs by reshaping trophic level relationship (Byrnes, 
97 Reynolds \& Stachowicz, 2007). In this sense, it is not trivial to study the behavior of food webs 98 to local species extinctions since it can be a suitable proxy of community response to alterations. Although much is known about macroalgae species and the environmental changes that Potter Cove is facing, there is a lack of information of how local extinctions of macroalgae species might impact on other species of the Cove and on the community as a whole. In this work we study the robustness of Potter Cove food web by simulating primary loss of macroalgae species using a topological approach. We hypothesized that the loss of these species from Potter Cove food web will generate a cascade of secondary extinctions that will lead the food web to collapse by a bottom-up mechanism. The aim of this study was to explore the robustness of Potter Cove food web to local extinctions of macroalgae species as possible consequences from ongoing climate change.

\section{Materials and methods}

\section{Study site}

Potter cove is a WAP fjord of $4 \mathrm{~km}$ long and $2.5 \mathrm{~km}$ wide, on the southern coast of $25 \mathrm{de}$ Mayo/King George Island $\left(62^{\circ} 14^{\prime} \mathrm{S}, 58^{\circ} 40^{\prime} \mathrm{W}\right)$, the largest of the South Shetlands Archipelago (Fig. 1). It is adjacent to Maxwell Bay, which connects to the Bransfield Strait. Water circulation in Potter Cove is strongly influenced by the general circulation of Maxwell Bay (Roese \& Drabble, 1998). The fjord is divided into an outer and an inner Cove which differ in bottom characteristics (Klöser et al., 1994; Klöser, Quartino \& Wiencke, 1996). The outer Cove consists of hard substrate of solid rocks and big boulders, whereas the inner part is dominated by soft sediments with high presence of muddy substrate. The rocky shores of the outer Cove are colonized by a large biomass of macroalgae (Klöser et al., 1996; Quartino et al., 2005), while the inner Cove has one of the highest concentrations of benthic filter feeders found in Antarctic coastal areas representing a hotspot of biodiversity (Sahade et al., 1998; Tatián et al., 1998; Tatián et al., 2004; Grange \& Smith, 2013).

\section{Food web dataset}

We based our analysis on the food web presented by Marina et al. (2018). Potter Cove food web includes 91 trophic species comprising algae, amphipods, isopods, sponge, gastropods, bivalves, echinoderms, fishes, among others, and compromising 308 trophic interactions, with a mean trophic level of $2.1( \pm 0.9)$ and a maximum trophic level of 4.27 (Fig. 2). It is important to note that, within the 91 trophic species, 24 correspond to macroalgae species and 2 to detritus sources, fresh and aged detritus. This food web model was constructed based primarily upon studies within the framework of international research cooperation between Argentina and Germany initiated in 1994 (Wiencke et al., 1998; Wiencke et al., 2008). Further details on the construction and properties of the network can be found in Marina et al. (2018).

\section{Common-enemy graph}


133 The analysis of secondary graphs is a useful tool for the study of food webs. Any food web can

134

135

136

137

138

139

140

141

142

143

144

145

146

147

148

149

150

151

152

153

154

155

156

157

158

159

160

161

162

163

164

165

166

167

168

169

170

171

be associated with two non-directed graphs: the niche overlap graph and the common-enemy or resource graph. The former is constructed by linking consumers that share at least one prey in common, and the latter is constructed by linking prey that share at least one consumer in common (Bersier, 2007). Common-enemy graphs provide a representation of indirect interactions within species of the food web. One of these possible indirect interactions is apparent competition, where an increase in prey abundance produces a decrease in another prey of a shared predator, not by direct competition but through an increase in the abundance of this shared predator (Holt \& Lawton, 1994). Additionally, the common-enemy graph is useful to know the number of predators that each species share and to compare this number with the degree obtained from the original food web. If a positive correlation exists; we expect a low number of secondary extinctions because more connected species also share a large number of predators. Also, common-enemy graphs represent an approximation to the complexity of the food web because they describe the map of indirect interactions that remain between preys. Such interactions may trigger cascading effects that involve positive and negative impacts on the abundance of prey populations (Holt \& Lawton, 1994). The common-enemy graph for Potter Cove food web was obtained by multiplying the original predation matrix (or adjacency matrix as it is classically known in food web literature) by its transpose, considering only those nodes that represent basal species (i.e. species without preys).

\section{Extinctions by topological approach}

The method used in this study is based on the topological approach of secondary extinctions (Albert, Jeong \& Barabasi, 2000) with the incorporation of extinctions thresholds (Schleuning et al., 2016; Bellingeri \& Bodini, 2013). The topological approach focuses exclusively on the presence or absence of consumer-resource relationships, taking into account only the qualitative network structure (i.e. its topology). In this manner, secondary extinctions occur when one consumer species lose all of its prey species (Solé \& Montoya, 2001). This approach has the advantage of requiring only the network structure as input, simplifying its application to large complex networks. However, it has its limitations due to the fact that species are lost secondarily only if all of its preys are removed. It is also assumed that all species have the same baseline probability of extinctions, whereas in natural systems some species are more vulnerable than others (Eklöf, Tang \& Allesina, 2013). One possibility to reduce such limitations is incorporate thresholds of extinctions that allow to model secondary extinctions of species which have not necessarily lost all of their preys. Schleuning et al. (2016) applied this approach to mutualistic networks, while Bellingeri \& Bodini (2013) did it in food webs. Bellingeri \& Bodini (2013) define threshold $(v)$ as the minimum level of energy necessary for species' survival. After each node removal, the fraction of original incoming energy $e(i)$ is calculated for each species, and the species $i$ is secondarily lost if this fraction is equal or less than the threshold (i.e. $e(i) \leq v)$. For example, a value of $v=0.25$ means that species $i$ goes extinct if $e(i)$ is equal or less than $25 \%$, when the $75 \%$ of the inflow is lost. In the classical topological approach, $v$ is implicitly assumed 
172 to be equal to 0 , and a species goes extinct when its energy inflow is null (Bellingeri \& Bodini, 173 2013). Since Potter Cove food web lacks energy flows information, it is necessary to assume that 174 all preys contribute equally to its predator diets and redefine $v$ concept as the fraction of 175 incoming links $l(i)$ from original ones that species $i$ needs to survive after a primary loss (i.e. 176 species $i$ is considered secondary loss when $l(i) \leq v)$. We performed diversity loss simulations of 177 macroalgae species (and detritus) of Potter Cove food web. Simulations consisted in removal of 178 target species from the predation matrix by deleting row and columns (primary extinction). 179 Following each primary extinction, we looked for secondary extinctions in a recursive manner as 180 follows. We computed an intermediate predation matrix where each $l(i)$ was calculated and

181

182

183

184

185

186

187

188

189

190

191

192

193

194

195

196

197

198

199

200

201

202

203

204

205

206

207

208

209

210

211 compared to the set extinction threshold. If $l(i)$ was equal or less that $v$, species $i$ was removed from the intermediate predation matrix, thus leading to a secondary extinction, and a new intermediate matrix was computed. This procedure was repeated until no $l(i)$ was less than $v$ and a final predation matrix was obtained. Then the final predation matrix was characterized by computing the number of species $(S)$, the number of trophic interactions or links $(L)$ and connectance $\left(C=L / S^{2}\right)$, (Pimm, 2002; Cohen, 1989), and was used as an input for a new primary loss simulation. This procedure was repeated until all macroalgae species were removed (an explicit example is presented in Supplementary Material: Fig. S1). Since the extinction procedure is carried out until all secondary extinctions are recorded, all the remaining species in the food web are connected to at least one basal species (i.e. they had at least one path that connected them to a basal producer). It is important to note that there are other basal species in Potter Cove food web different from macroalgae species. Therefore a non-null final predation matrix is possible given that there are species that depend on other sources (e.g. phytoplankton).

Macroalgae species were removed from the predation matrix according to different removal sequences established by the degree of each macroalgae (total number of trophic interactions per node) and total biomass in Potter Cove. Four sequences of extinctions were used: random order, degree in ascending and descending order, and biomass order in ascending order. The sequences established by the species' degree depended only on the food web structure, and in consequence all macroalgae species could be eliminated following these sequences. According to Sole \& Montoya (2001), we expected that descending order sequence presented the more abrupt changes, and eliminations in random order set an intermediate situation between ascending and descending order. Thus, the upper and lower limits in which the parameters of the network could vary are established by descending and ascending order. We decided to eliminate macroalgae from lower values of biomass to higher values (i.e. in ascending order of biomass) since extinction risk is typically high for rare species, because small populations are more vulnerable to environmental and demographic stochasticity than larger ones (Lawton, 1994; McKinney, 1997). In this way, we eliminated 20 macroalgae species based on biomass data obtained by Quartino \& Boraso de Zaixso (2008a). Extinction simulations were performed varying $v$ (0\%, 25 $\%, 50 \%$ and $75 \%$ ), and 100 repetitions were randomly performed for the sequences: random, ascending and descending degree orders. As a consequence, we had four different responses per topological parameter ( $L$ vs primary extinctions, $C$ vs primary extinctions and secondary 
212 extinctions vs primary extinctions). After the loss of all macroalgae species, we simulated the

213

214

215

216

217

218

219

220

221

222

223

224

225

226

227

228

229

230

231

232

233

234

235

236

237

238

239

240

241

242

243

244

245

246

removal of the two detritus sources (fresh and aged) given that macroalgae species are the main source of these types of detritus in Potter Cove ecosystem (Quartino, Boraso de Zaixso \& Momo, 2008b). We tested whether there was a correlation between large-biomass and high-degree macroalgae species by computing the Pearson's correlation coefficient. The impact of secondary extinctions in the food web, was assessed considering the percentage of species loss by secondary extinction with respect to maximum number of possible extinctions (i.e all non-basal species) which corresponded to 61 species. The $v$ complement $(100 \%-v)$ indicates the percentage of prey that a predator has to lose to go extinct. We compared the $v$ complement with the percentage of secondary extinctions in order to assess the effect of macroalgae loss in the whole food web. A percentage of secondary extinction greater than the $v$ complement indicates a collapse of the food web produced by the instability of the network and not because of individual effects.

\section{Testing Thresholds}

To test the importance of $v$ in secondary extinctions, we simulated the primary loss of a given quantity of macroalgae species choosing at random the identity of them. We varied $v$ from 5 to $95 \%$ by $5 \%$, and recorded the number of secondary extinctions for each $v$ value. These simulations were performed increasing the number of macroalgae primary losses: 3, 5, 10, 15 and 20 species. We obtained mean and confidence interval values for the five quantities analyzed. Then, we plotted secondary extinctions vs $v$.

The GNU R software (R Core Team, 2017, version 3.4.2) was used for food web simulations and matrix computations, and Visone (Brandes \& Wagner, 2004, version 2.9.2) was used to plot Potter Cove food web and the common-enemy graph.

\section{Results}

\section{Common-enemy graph}

The common-enemy graph of basal species from Potter Cove food web had all species connected with a high density of 9.53 interactions per node (Fig. 2). It compromised 30 species consisting of: 24 macroalgae species, 2 sources of diatoms (i.e. benthic and epiphytic), one node representing phytoplankton and 3 non-living nodes corresponding to fresh, aged detritus and necromass. Among all the links of the graph (286 indirect interactions), most of them (222) were between macroalgae species. However, fresh detritus and benthic diatoms shared the maximum number of common predators (11). There was a high correlation between the degree of each macroalgae species obtained from the original food web and the number of shared predators calculated from the common-enemy graph (Pearson's correlation coefficient 0.87 ).

Extinctions by topological approach 
247 As the number of primary extinctions increased, $L$ of the remaining food web decreased irrespectively of $v$ (Fig. 3). Removal in a descending order, from highest to lowest degree, showed a fast loss of $L$ at the beginning; while the removal in ascending order showed a slow loss of $L$. Random order resulted in an intermediate position between ascending and descending degree sequences. Elimination of macroalgae species based on biomass order displayed a response very similar to the response of the removal in ascending degree order at first, and then it behaved as the random extinctions sequence with a similarity that increased with $v$. There was a low correlation between macroalgae biomass and degree (Pearson's correlation coefficient 0.27), which means macroalgae of high biomass did not necessarily have a high degree in Potter Cove food web. When we compared the responses at different $v$, we found that an increase in $v$ led to an increase in the number of lost interactions $\left(L_{\min }\right.$ values of 211, 197, 129, and 30 for $v$ of 0,25 , 50 , and $75 \%$, respectively).

The response of $C$ to extinctions differed from $L$ response pattern (Fig. 4). At low $v(0 \%$ and 25 $\%), C$ increased with primary extinctions. Regarding this, removal in descending order led to a slow increment of $C$. On the other hand, the loss of low connected species was associated with a high slope in the curve, meaning that the elimination of species by ascending degree led to a rapid increase of $C$. Random removal depicted an intermediate situation between ascending and descending degree sequences. Elimination based on biomass order displayed a similar response to that of removal in ascending order. An increase in $C$ is directly associated to the way it is computed, as possible interactions $\left(S^{2}\right)$ increased faster than real interactions $(L)$. At high $v(50 \%$ and $75 \%), C$ increased for all sequences but showed fluctuations.

We observed a general trend of increase of secondary extinctions with the number of primary losses (Fig. 5), and also with $v(6.5,9.8,29.5$, and $70.5 \%$ of secondary extinctions with $v$ of 0 , 25, 50, and $75 \%$, respectively). This increase of secondary extinctions is expected because species lose a greater number of preys as the number of incoming links decrease, which leads $l(i)$ to be less than $v$. Among the elimination sequences, we observed that elimination in descending degree reached maximum number of secondary extinctions in less number of steps than the others sequences and the elimination in ascending degree was the last sequence to reach it. Biomass and random sequences exhibited an intermediate response between the ascending and descending degree order, overlapping in several points.

\section{Testing thresholds}

While increasing $v$ value, the number of secondary extinctions increased independently of the number of primary extinctions. In all cases, there was an inflection point in $v$ value that triggered a great number of secondary extinctions. Such inflection point appeared at a lower $v$ value as the number of primary loss increased. It is worth noting that, for all cases, this trigger was generated at a $v$ value greater than $50 \%$ (Fig. 6).

\section{Discussion}

We found that Potter Cove food web is relatively stable to macroalgae loss. A significant number of secondary extinctions were obtained beyond a $50 \%$ threshold $(v)$. Indeed, to observe a real 
286

287

288

289

290

291

292

293

294

295

296

297

298

299

300

301

302

303

304

305

306

307

308

309

310

311

312

313

314

315

316

317

318

319

320

321

322

323

324

collapse where the percentage of secondary extinctions is greater than $v$ complement, a $v$ of $75 \%$ was needed. A $v$ of $75 \%$ means predators cannot survive if they have less than $75 \%$ of their original prey set, a very extreme and unreal condition. Bellingeri \& Bodini (2013) showed that reducing only $10 \%$ of prey intake, a disproportionate growth of secondary extinctions emerged. Allesina, Bodini \& Bondavalli (2006) also found a similar result imposing link thresholds equal to $15 \%$. Our results do not support the hypothesis that the elimination of macroalgae species from Potter Cove food web will generate a cascade of secondary extinctions, and thus suggests that Potter Cove food web could be more robust than similar ecological networks (Allesina, Bodini \& Bondavalli, 2006; Bellinger \& Bodini, 2013). We found that macroalgae of high degree were positively correlated with those that shared more predators, which indicates that these macroalgae species are functionally redundant (i.e. species with equivalent trophic interactions). Functional redundancy has important consequences in potential cascade extinctions, since it increases food web resistance by means of availability of alternative preys (Borrvall et al., 2000). Functional redundancy and omnivory explain why a high $v$ has to be reached to observe a high number of secondary extinctions. Functional redundancy and omnivory could be the result of a long evolution time and extreme conditions of the studied ecosystem where the preferred strategy is to be a generalist (i.e. species with many feeding links). Redundancy appears to be the rule in many food webs, with stabilizing effects (Lawton \& Brown, 1994; Borrvall et al., 2000; Worm \& Duffy, 2003; Thompson et al., 2007; Sanders et al., 2018).

The common-enemy graph has a high density value of interactions per node. Similar values were obtained in studies of rocky intertidal ecosystems in Patagonia (Fueyo Sanchez, 2013). The presence of subnets in common-enemy graphs is usually associated with the identification of habitat structures (Holt \& Lawton, 1994). The common-enemy graph for Potter Cove food web exhibited no subnets, consistent with the marine nature of this food web (Marina et al., 2018). Given the high density of the common predators network, it is very difficult to predict indirect relationships between species, as each interaction involves positive and negative effects between species abundances (Holt \& Lawton, 1994). The high density of this graph also suggests the presence of high redundancy in the food web.

Montoya \& Solé (2002) have shown that the elimination of the most connected species causes the greatest number of secondary extinctions. As expected, removing the most connected macroalgae from Potter Cove food web produced a fast secondary species loss, and the same happened for the number of links $(L)$. Connectance $(C)$ increased with extinction for all deletion sequences, which is explained by the number of possible interactions $\left(S^{2}\right)$ decreasing faster than the number of real interactions $(L)$. However, the number of secondary extinctions remained low even when $v$ was quite high (75\%). Analyses of potential secondary extinctions showed that marine food webs appear to be robust to the loss of the most connected species as well as random species (Dunne, Williams \& Martinez, 2004). It is important to note that the elimination of species in biomass order generated a similar general response in $L, C$ and secondary extinctions 
325

326

327

328

329

330

331

332

333

334

335

336

337

338

339

340

341

342

343

344

345

346

347

348

349

350

351

352

353

354

355

356

357

358

359

360

361

362

363

than the loss of the most connected macroalgae species, especially at the first removals and when $v$ was increased. Nevertheless, there was no correlation between large-biomass and high-degree species. This similarity response could be explained because both criteria involved key species that produced an emerging effect on the food web. This means that large-biomass and highdegree species are acting as source for species with few trophic interactions or low redundancy, and this in turn produces a great number of secondary extinctions.

Even though the number of secondary extinctions was low, a clear impact on the emergent properties of the network such as $L$ and $C$ was observed when macroalgae species were lost. These changes could have a significant impact on the fragility and resilience of Potter Cove food web altering the dynamics of the system. Dynamical analyses of the response of communities to species loss usually predict a higher number of secondary extinctions than topological ones (Eklöf \& Ebenman, 2006). The main difference between topological and dynamical approaches is that the topological analyses cannot detect indirect effects, as top-down extinctions caused by the loss of a top predator, while dynamical analyses can detect this type of indirect effects (Ebenman \& Jonsson, 2005). In this way, the topological approach underestimates the actual number of secondary extinctions, and in consequence overestimates food web robustness. However, the topological approach enables the analysis of more complex food webs, since it only requires knowledge of network structure (Eklöf, Tang \& Allesina, 2013). Dynamical analyses have also found that the effect of interaction strengths has important consequences on food web stability (Allesina, Bodini \& Bondavalli, 2006; Bellingeri \& Bodini 2013). Furthermore, we have to consider that this food web includes all recorded trophic interactions, though trophic interactions do not always occur simultaneously in time and space. We cannot ignore the additional potentially confounding effects of seasonality and spatial sampling (Ings et al., 2009). In fact, the network represents an ideal niche space and dynamic stability depends more on how interactions materialized in time and space. Some nodes are clearly pulsatile, such as the massive influx of Krill (Aguirre, 2015), which it is difficult to reflect in a static description of the network topology. The consideration of all these factors might increase the fragility of Potter Cove food web. By reducing the number of possible interactions, predators cannot switch to alternative preys, depending solely on preys that are present and available. For these reasons, future studies considering the effect of time and space, massive pulses of certain species and the strength of each interaction are required to satisfactory predict the impacts of climate change on the currently threatened Antarctic marine ecosystem of Potter Cove.

\section{Conclusions}

We found that Potter Cove food web was relatively robust to local extinctions of macroalgae species under a topological approach considering extinction thresholds $(v)$. We could attribute this robustness to the effects of omnivory and functional redundancy (Borrvall et al., 2000). This robustness becomes clear in the high link density of the common-enemy graph. Therefore, we expect Potter Cove food web to be moderately affected by the changes in macroalgae species caused by climate change until a high threshold of stress is reached, and then negative effects are 
364

365

366

367

368

369

370

371

372

373

374

375

376

377

378

379

380

381

382

383

384

385

386

387

388

389

390

391

392

393

394

395

396

397

expected to spread through the entire food web leading it to collapse. In this manner, our results suggest that, despite the apparent robustness of Potter Cove food web, structural changes in the community might not be detected until most of the macroalgae species are affected.

\section{Acknowledgments}

We thank Kevin Sánchez and Florencia Ríos for suggestions on language aspects, which helped us to improve the manuscript. We also thank the editor and the two reviewers for their valuable comments which helped us improving the quality and clearness of this paper.

\section{Figure Texts}

Figure 1. Map of Potter Cove at 25 de Mayo/King George Island where scientific research station Base Carlini is highlighted (Map data: (C2018 Google Earth, DigitalGlobe). 25 de Mayo/King George Island is the largest island of the South Shetland Islands, lying $120 \mathrm{~km}$ Western Antarctic Peninsula (WAP).

Figure 2. A: common-enemy graph of Potter Cove food web, nodes represent basal species and links indirect interactions (shared predators). Node and link widths are proportional to number of shared predators. B: Potter Cove food web, vertical position indicates trophic level and node widths are proportional to total degree (in and out) (Marina et al., 2018). Node colors represent functional groups.

Figure 3. Remaining links $(L)$ vs primary extinctions, when macroalgae species and detritus were removed. $L$ was recorded after primary and secondary extinctions have taken place. Each box corresponds to a different threshold $(v)$ (A: $0 \%$, B: $25 \%, \mathrm{C}: 50 \%$ and D: $75 \%$ ). Macroalgae loss was done following different sequences of extinctions: red, ascending degree (mean and standard deviation); blue, descending degree (mean and standard deviation); violet, random degree (mean and standard deviation) and green, biomass (ascending order).

Figure 4. Connectance $(C)$ vs primary extinctions, when macroalgae species and detritus were removed. $C$ was computed after primary and secondary extinctions have taken place. Each box corresponds to a different threshold (v) (A: $0 \%$, B: $25 \%$, C: $50 \%$ and D: $75 \%)$. Macroalgae loss was done following different sequences of extinctions: red, ascending degree (mean and standard deviation); blue, descending degree (mean and standard deviation); violet, random degree (mean and standard deviation) and green, biomass (ascending order).

Figure 5. Secondary extinctions vs primary extinctions, when macroalgae species and detritus were removed. Each box corresponds to a different threshold (v) (A: $0 \%$, B: $25 \%$, C: $50 \%$ and D: $75 \%$ ). Macroalgae loss was done following different sequences of extinctions: red, ascending degree (mean and standard deviation); blue, descending degree (mean and standard deviation); violet, random degree (mean and standard deviation) and green, biomass (ascending order). 
398

399

400

401

402

403

404

405

406

407

408

409

410

411

412

413

414

415

416

417

418

419

420

421

422

423

424

425

426

427

428

Figure 6. Secondary extinctions with threshold $(v)$ variations (from $5 \%$ to $95 \%$ by $5 \%$ ) when macroalgae are primary lost (blue: three, brown: five, green: ten, red: fifteen, pink: twenty). Points are means of secondary extinctions when $x$ number of primary extinctions took place at a particular $v$ (by random simulations). Shaded area represents confidence interval of the series.

Figure S1. Scheme of the methodology used to detect secondary extinctions after the removal of a particular species (primary loss). In this example, the extinction threshold (v) was 0.75 and $\mathrm{H} 2$, $\mathrm{P} 1$ and P2 species were secondarily extinct when their fraction of incoming links $l(i)$ was lower than $v$ after the removal of species A3. A1, A2 and A3 represent algae species, H1 and H2 herbivores, and $\mathrm{P} 1$ and $\mathrm{P} 2$ predators.

\section{REFERENCE}

Aguirre G. (2015). Ecología del mesozooplancton marino en ambientes costeros de altas latitudes: Canal Beagle (extremo sur de Sudamérica) y Caleta Potter (Isla 25 de Mayo, Antártida). D. Phil. Thesis, University of Buenos Aires.

Albert, R, Jeong, H \& Barabasi, AL. (2000) Error and attack tolerance of complex networks. Nature, 406:378-382.

Allesina, S, Bodini, A, \& Bondavalli, C. (2006). Secondary extinctions in ecological networks: bottlenecks unveiled. Ecological Modelling, 194(1-3): 150-161.

Bascompte, J. (2009). Disentangling the web of life. Science, 325(5939): 416-419.

Bellingeri, M, \& Bodini, A. (2013). Threshold extinction in food webs. Theoretical ecology, 6(2): 143-152.

Bers, AV, Momo, F, Schloss, IR, \& Abele, D. (2013). Analysis of trends and sudden changes in long-term environmental data from King George Island (Antarctica): relationships between global climatic oscillations and local system response. Climatic change, 116(3-4): 789-803.

Bersier, LF. (2007). A history of the study of ecological networks. In: Kepes F. ed. Biological Networks. Complex systems and inter-disciplinary science Series, World Scientific, Singapour, 3(11): 365-421.

Borrvall, C, Ebenman, B, Jonsson, T, \& Jonsson, T. (2000). Biodiversity lessens the risk of cascading extinction in model food webs. Ecology Letters, 3(2): 131-136.

Brandes, U, \& Wagner, D. (2004). Visone - Analysis and Visualization of Social Networks. In Michael Jünger and Petra Mutzel (Eds.): Graph Drawing Software, pp. 321-340. (C) SpringerVerlag. 
429 Bromwich, DH, Nicolas, JP, Monaghan, AJ, Lazzara, MA, Keller, LM, Weidner, GA, \& Wilson, 430 AB. (2013). Central West Antarctica among the most rapidly warming regions on Earth. Nature 431 Geoscience, 6(2): 139-145.

432 Byrnes, JE, Reynolds, PL, \& Stachowicz, JJ. (2007). Invasions and extinctions reshape coastal 433 marine food webs. PloS one, 2(3): e295.

434 Campana, GL, Zacher, K, Deregibus, D, Momo, FR, Wiencke, C, \& Quartino, ML. (2018). 435 Succession of Antarctic benthic algae (Potter Cove, South Shetland Islands): structural patterns 436 and glacial impact over a four-year period. Polar Biology, 41(2): 377-396.

437 Curtsdotter, A, Binzer, A, Brose, U, de Castro, F, Ebenman, B, Eklöf, A, Riede JO, Thierry A \& 438 Rall, BC. (2011). Robustness to secondary extinctions: comparing trait-based sequential 439 deletions in static and dynamic food webs. Basic and Applied Ecology, 12(7): 571-580.

440 Deregibus, D, Quartino, ML, Campana, GL, Momo, FR, Wiencke, C, \& Zacher, K (2016). 441 Photosynthetic light requirements and vertical distribution of macroalgae in newly ice-free areas 442 in Potter Cove, South Shetland Islands, Antarctica. Polar Biology, 39(1): 153-166.

443 de Santana, CN, Rozenfeld, AF, Marquet, PA, \& Duarte, CM. (2013). Topological properties of 444 polar food webs. Marine ecology progress series, 474: 15-26.

445 Donohue, I, Petchey, OL, Kéfi, S, Génin, A, Jackson, AL, Yang, Q, \& O'Connor, NE. (2017). 446 Loss of predator species, not intermediate consumers, triggers rapid and dramatic extinction 447 cascades. Global Change Biology, 23(8): 2962-2972.

448 Ducklow, HW, Fraser, WR, Meredith, MP, Stammerjohn, SE, Doney, SC, Martinson, DG \& 449 Amsler, CD. (2013). West Antarctic Peninsula: an ice-dependent coastal marine ecosystem in 450 transition. Oceanography, 26(3): 190-203

451 Dunne, JA, Williams, RJ, \& Martinez, ND. (2002). Food-web structure and network theory: the 452 role of connectance and size. Proceedings of the National Academy of Sciences, 99(20): 1291745312922.

454 Dunne, JA, Williams, RJ, \& Martinez, ND. (2004). Network structure and robustness of marine 455 food webs. Marine Ecology Progress Series, 273: 291-302.

456 Dulvy, NK, Metcalfe, JD, Glanville, J, Pawson, MG, \& Reynolds, JD. (2000). Fishery stability, 457 local extinctions, and shifts in community structure in skates. Conservation Biology, 14(1): 283458293.

459 Ebenman, B, Law, R \& Borrvall, C. (2004). Community viability analysis: the response of 460 ecological communities to species loss. Ecology, 85(9): 2591-2600. 
461 Eklöf, A, \& Ebenman, BO. (2006). Species loss and secondary extinctions in simple and 462 complex model communities. Journal of animal ecology, 75(1): 239-246.

463 Eklöf, A, Tang, S, \& Allesina, S. (2013). Secondary extinctions in food webs: a Bayesian 464 network approach. Methods in Ecology and Evolution, 4(8): 760-770.

465

466

467

468

469

470

471

472

473

474

475

476

477

478

479

480

481

482

483

484

485

486

487

488

489

490

491

492

493

Ellison, AM, Bank, MS, Clinton, BD, Colburn, EA, Elliott, K, Ford, CR, Foster, DR, Kloeppel, BD, Knoepp, JD, Lovett GM, Mohan, J, Orwing, DA, Rodenhouse NL, Sobczak, WV, Stinson, KA, Stone, Swan, CM, Thompson, J, Von Holle, B, \& Webster, JR. (2005). Loss of foundation species: consequences for the structure and dynamics of forested ecosystems. Frontiers in Ecology and the Environment, 3(9): 479-486.

Fueyo Sánchez, L. (2013). Estructura de redes tróficas y flujos de energía en comunidades intermareales de la costa argentina. D. Phil. Thesis. National University of Mar del Plata.

Gómez, I, Wulff, A, Roleda, MY, Huovinen, P, Quartino, ML, Dunton, K \& Wiencke, C. (2009) Light and temperature demands of marine benthic microalgae and seaweeds in polar regions. Botanica Marina, 52: 593-608. doi: 10.1515/BOT.2009.073

Grange, LJ, \& Smith, CR. (2013). Megafaunal communities in rapidly warming fjords along the West Antarctic Peninsula: hotspots of abundance and beta diversity. PloS one, 8(12): e77917.

Hastings, A, McCann, KS, \& de Ruiter, PC. (2016). Introduction to the special issue: theory of food webs. Theoretical Ecology, 9(1): 1-2.

Holt, RA, \& Lawton, JH. (1994). The ecological consequences of shared natural enemies. Annual review of Ecology and Systematics, 25(1): 495-520.

Ings, TC, Montoya, JM, Bascompte, J, Blüthgen, N, Brown, L, Dormann, CF \& Lauridsen, RB. (2009). Review: Ecological networks-beyond food webs. Journal of Animal Ecology, 78(1): 253-269.

Jackson, JB, Kirby, MX, Berger, WH, Bjorndal, KA, Botsford, LW, Bourque, BJ, Bradbury, RH, Cooke, R, Erlandson, J, Estes, JA, Hughes, TP, Kidwell, S, Lange, CB, Lenihan, HS, Pandolfi, JH, Peterson, CH, Steneck, RS, Tegner, MJ, \& Hughes, TP. (2001). Historical overfishing and the recent collapse of coastal ecosystems. Science, 293(5530): 629-637.

Klöser, H, Mercuri, G, Laturnus, F, Quartino, ML, \& Wiencke, C. (1994). On the competitive balance of macroalgae at Potter Cove (King George Island, South Shetlands). Polar Biology, 14(1): 11-16.

Klöser, H, Quartino, ML, \& Wiencke, C. (1996). Distribution of macroalgae and macroalgal communities in gradients of physical conditions in Potter Cove, King George Island, Antarctica. Hydrobiologia, 333(1): 1-17. 
494 Lagger, C, Nime, M, Torre, L, Servetto, N, Tatián, M, \& Sahade, R. (2017). Climate change, 495 glacier retreat and a new ice-free island offer new insights on Antarctic benthic responses. 496 Ecography, 41(4): 579-591.

497 Lawton, JH. (1994). Population dynamic principles. Phil. Trans. R. Soc. Lond. B, 344(1307): 6149868.

499 Lawton, JH, \& Brown, VK. (1994). Redundancy in ecosystems. In Biodiversity and ecosystem 500 function (pp. 255-270). Springer, Berlin, Heidelberg.

501 Marina, T, Salinas, V, Cordone, G, Campana, G, Moreira, ME, Deregibus, D, Torre, L, Sahade, 502 R, Tatián, M, Barrera Oro, E, De Troch, M, Doyle, S, Quartino, ML, Saravia, L, \& Momo, F. 503 (2018). The food web of Potter Cove (Antarctica): complexity, structure and function Estuarine, 504 Coastal and Shelf Science, 200: 141-151. doi:10.1016/j.ecss.2017.10.015.

505 McClintock, J, Ducklow, H, \& Fraser, W. (2008). Ecological Responses to Climate Change on 506 the Antarctic Peninsula: The Peninsula is an icy world that's warming faster than anywhere else 507 on Earth, threatening a rich but delicate biological community. American Scientist, 96(4): 302508310.

509 McKinney, ML. (1997). Extinction vulnerability and selectivity: combining ecological and 510 paleontological views. Annual Review of Ecology and Systematics, 28(1): 495-516.

511 Memmott, J, Waser, NM, \& Price, MV. (2004). Tolerance of pollination networks to species 512 extinctions. Proceedings of the Royal Society of London. Series B: Biological Sciences, 271: $513 \quad 2605-2611$.

514 Montoya, JM, \& Solé, RV. (2002). Small world patterns in food webs. Journal of theoretical 515 biology, 214(3): 405-412.

516 Neushul M. (1965) Diving observation of sub-tidal Antarctic marine vegetation. Botanica 517 marina, 8(2-4): 234-243.

518 Nicolas, JP, \& Bromwich, DH. (2014). New reconstruction of Antarctic near-surface 519 temperatures: Multidecadal trends and reliability of global reanalyses. Journal of Climate, 520 27(21): 8070-8093.

521 Pasotti, F, Manini, E, Giovannelli, D, Wölfl, AC, Monien, D, Verleyen, E, Braeckman, U, 522 Abele, D \& Vanreusel, A. (2015). Antarctic shallow water benthos in an area of recent rapid 523 glacier retreat. Marine Ecology, 36(3): 716-733.

524 Quartino, ML, Zaixso, HE, \& Boraso de Zaixso, AL. (2005). Biological and environmental 525 characterization of marine macroalgal assemblages in Potter Cove, South Shetland Islands, 526 Antarctica. Botanica Marina, 48(3): 187-197. 
527 Quartino, ML, \& De Zaixso, AB. (2008a). Summer macroalgal biomass in Potter Cove, South 528 Shetland Islands, Antarctica: its production and flux to the ecosystem. Polar Biology, 31(3): 281529294.

530 Quartino, ML, Boraso de Zaixso A, Momo, FR. (2008b) Macroalgal production and the energy 531 cycle of Potter Cove. In: Wiencke, C, Ferreyra, GA., Abele, D,Marenssi, S. (Eds.), The 532 Antarctic ecosystem of Potter cove, King-George Island (Isla 25 de Mayo). Alfred-Wegener 533 Institut (AWI), Bremerhaven, pp. 68-74.

534 Quartino, ML, Deregibus, D, Campana, GL, Latorre, GEJ, \& Momo, FR. (2013). Evidence of 535 macroalgal colonization on newly ice-free areas following glacial retreat in Potter Cove (South 536 Shetland Islands), Antarctica. PloS one, 8(3): e58223.

537 R Core Team (2017). R: A language and environment for statistical computing. R Foundation for 538 Statistical Computing, Vienna, Austria. URL https://www.R-project.org/.

539 Roese, M, \& Drabble, M. (1998). Wind-driven circulation in Potter Cove. Berichte zur 540 polarforschung, 299: 40-46.

541 Sahade, R, Lagger, C, Torre, L, Momo, F, Monien, P, Schloss, I, Barnes, D, Servetto, N, 542 Tarantelli, S, Tatián, M, Zamboni, N \& Abele, D. (2015). Climate change and glacier retreat 543 drive shifts in an Antarctic benthic ecosystem. Science Advances, 1(10): e1500050.

544 Sahade, R, Tatián, M, Kowalke, J, Kühne, S, \& Esnal, GB. (1998). Benthic faunal associations 545 on soft substrates at Potter Cove, King George Island, Antarctica. Polar Biology, 19(2): 85-91.

546 Sanders, D, Sutter, L, \& Veen, FJ. (2013). The loss of indirect interactions leads to cascading 547 extinctions of carnivores. Ecology letters, 16(5): 664-669.

548 Sanders, D, Kehoe, R, Thebault, E, \& Van Veen, FJF. (2018). Trophic redundancy reduces 549 vulnerability to extinction cascades. Proceedings of the National Academy of Sciences, 115(10): $550 \quad 2419-2424$.

551 Schleuning, M, Fründ, J, Schweiger, O, Welk, E, Albrecht, J, Albrecht, M, Böhning-Gaese, KD, 552 Dehling, M, Dormann, CF, Exeler, N, Farwig, N, Harpke, A, Hickler, T, Kratochwil, A, 553 Kuhlmann, M, Kühn, I, Michez, D, Mudri-Stojnić, S, Plein, M, Rasmont, P, Schwabe, A, 554 Settele, J, Vujić, A, Weiner, CN, Wiemers, M \& Hof C. (2016). Ecological networks are more 555 sensitive to plant than to animal extinction under climate change. Nature Communications, 7: 55613965.

557 Schloss, IR, Abele, D, Moreau, S, Demers, S, Bers, AV, González, O, \& Ferreyra, GA. (2012). 558 Response of phytoplankton dynamics to 19 year (1991-2009) climate trends in Potter Cove 559 (Antarctica). Journal of marine Systems, 92(1): 53-66. doi:10.1016/j.jmarsys.2011.10.006 
560 Sorte, CJ, Davidson, VE, Franklin, MC, Benes, KM, Doellman, MM, Etter, RJ, Hanningan, RE, 561 Lubchenco J \& Menge, BA. (2017). Long-term declines in an intertidal foundation species 562 parallel shifts in community composition. Global change biology, 23(1): 341-352.

563 Sole, RV, \& Montoya, M. (2001). Complexity and fragility in ecological networks. Proceedings 564 of the Royal Society of London B: Biological Sciences, 268(1480): 2039-2045.

565 Tatián, M, Sahade, RJ, Doucet, ME, \& Esnal, GB. (1998). Ascidians (Tunicata, Ascidiacea) of 566 Potter Cove, South Shetland Islands, Antarctica. Antarctic science, 10(2): 147-152.

567 Tatian, M, Sahade, R, \& Esnal, GB. (2004). Diet components in the food of Antarctic ascidians 568 living at low levels of primary production. Antarctic Science, 16(02): 123-128.

569 Thompson, RM, Hemberg, M, Starzomski, BM, \& Shurin, JB. (2007). Trophic levels and trophic 570 tangles: the prevalence of omnivory in real food webs. Ecology, 88(3): 612-617.

571 Turner, J, Bindschadler, R, Convey, P, Di Prisco, G, Fahrbach, E, Gutt, J, Hodgson, DA, 572 Mayewski, PA, \& Summerhayes, C. (2009). Eds., Antarctic Climate Change and the 573 Environment (Scientific Committee on Antarctic Research, Scott Polar Research Institute, 574 Cambridge).

575 Wiencke, C, Ferreyra, G, Arntz, W, \& Rinaldi, C. (1998). The Potter Cove coastal ecosystem, 576 Antarctica. Berichte zur Polarforschung, 299: 1-106.

577 Wiencke, C, Ferreyra, GA, Abele, D, \& Marenssi, S. (2008). The Antarctic ecosystem of Potter 578 cove, King-George Island (Isla 25 de Mayo): Synopsis of research performed 1999-2006 at the 579 Dallmann Laboratory and Jubany Station. Berichte zur Polar-und Meeresforschung (Reports on 580 Polar and Marine Research), 571.

581 Witman, JD, Smith, F, \& Novak, M. (2017). Experimental demonstration of a trophic cascade in 582 the Galápagos rocky subtidal: Effects of consumer identity and behavior. PloS one, 12(4): $583 \mathrm{e} 0175705$.

584 Worm, B, \& Duffy, JE. (2003). Biodiversity, productivity and stability in real food webs. Trends 585 in Ecology \& Evolution, 18(12): 628-632. 
Figure 1

Map of Potter Cove at 25 de Mayo/King George Island

Map of Potter Cove at 25 de Mayo/King George Island where scientific research station Base

Carlini is highlighted (Map data: (c)2018 Google Earth, DigitalGlobe). 25 de Mayo/King George Island is the largest island of the South Shetland Islands, lying $120 \mathrm{~km}$ Western Antarctic Peninsula (WAP).

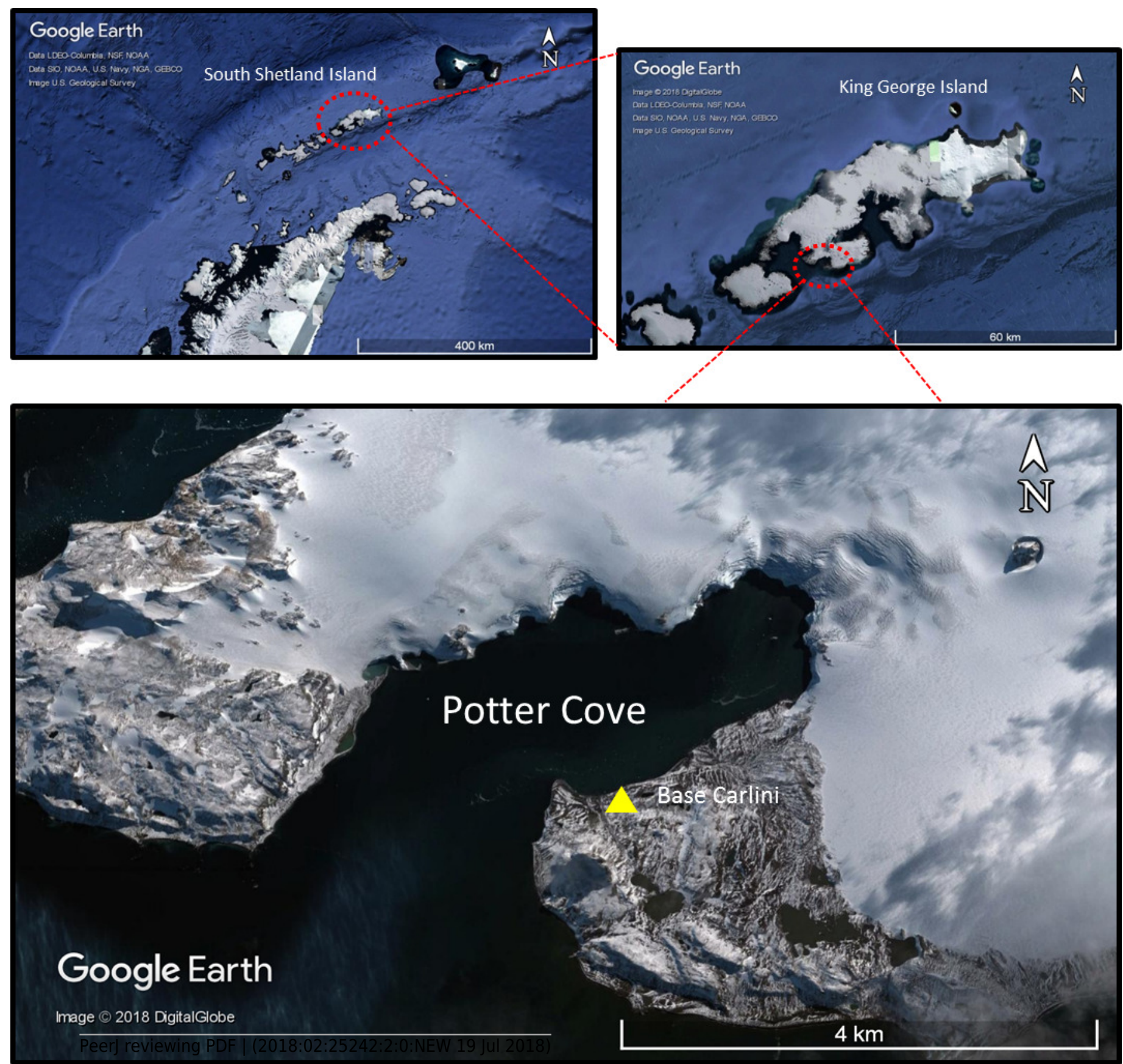


Figure 2

Common-enemy graph and Potter Cove food web

A: common-enemy graph of Potter Cove food web, nodes represent basal species and links indirect interactions (shared predators). Node and link widths are proportional to number of shared predators. B: Potter Cove food web, vertical position indicates trophic level and node widths are proportional to total degree (in and out) (Marina et al., 2018). Node colors represent functional groups.
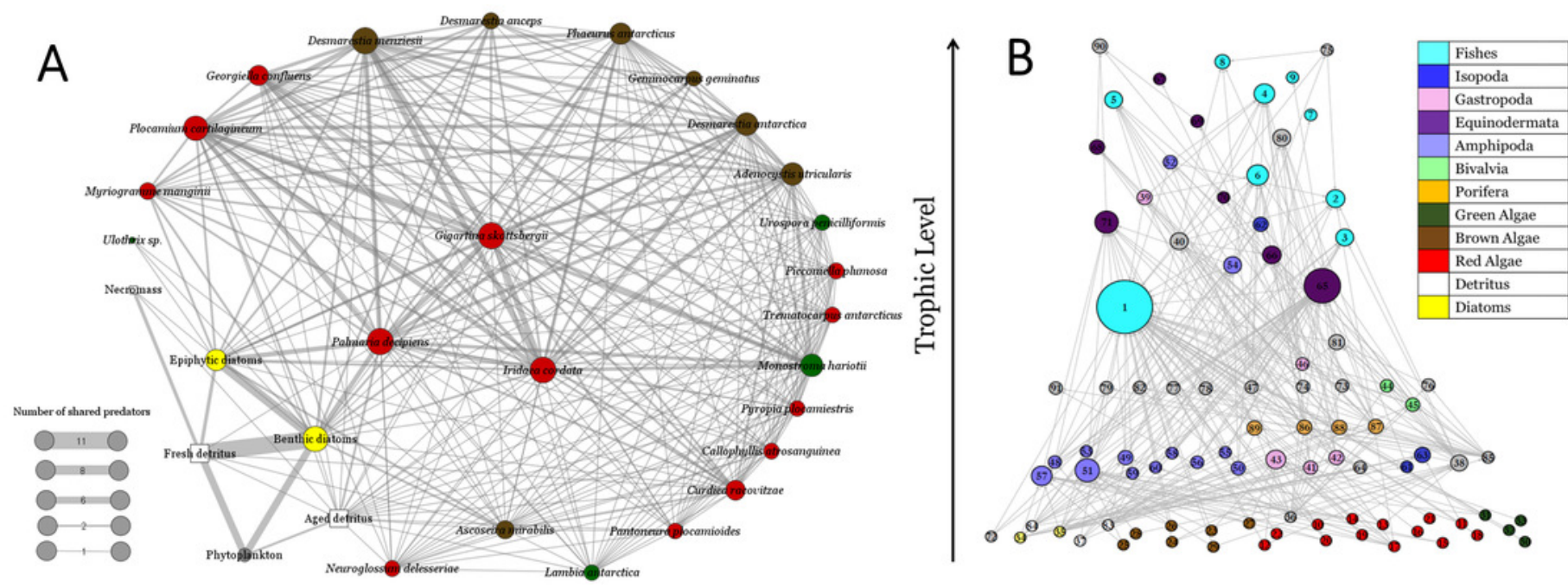


\section{Figure 3}

Links response to simulation of species loss

Remaining links $(L)$ vs primary extinctions, when macroalgae species and detritus were removed. $L$ was recorded after primary and secondary extinctions have taken place. Each box corresponds to a different threshold (v) (A: $0 \%$, B: $25 \%$, C: $50 \%$ and D: $75 \%$ ). Macroalgae loss was done following different sequences of extinctions: red, ascending degree (mean and standard deviation); blue, descending degree (mean and standard deviation); violet, random degree (mean and standard deviation) and green, biomass (ascending order). 

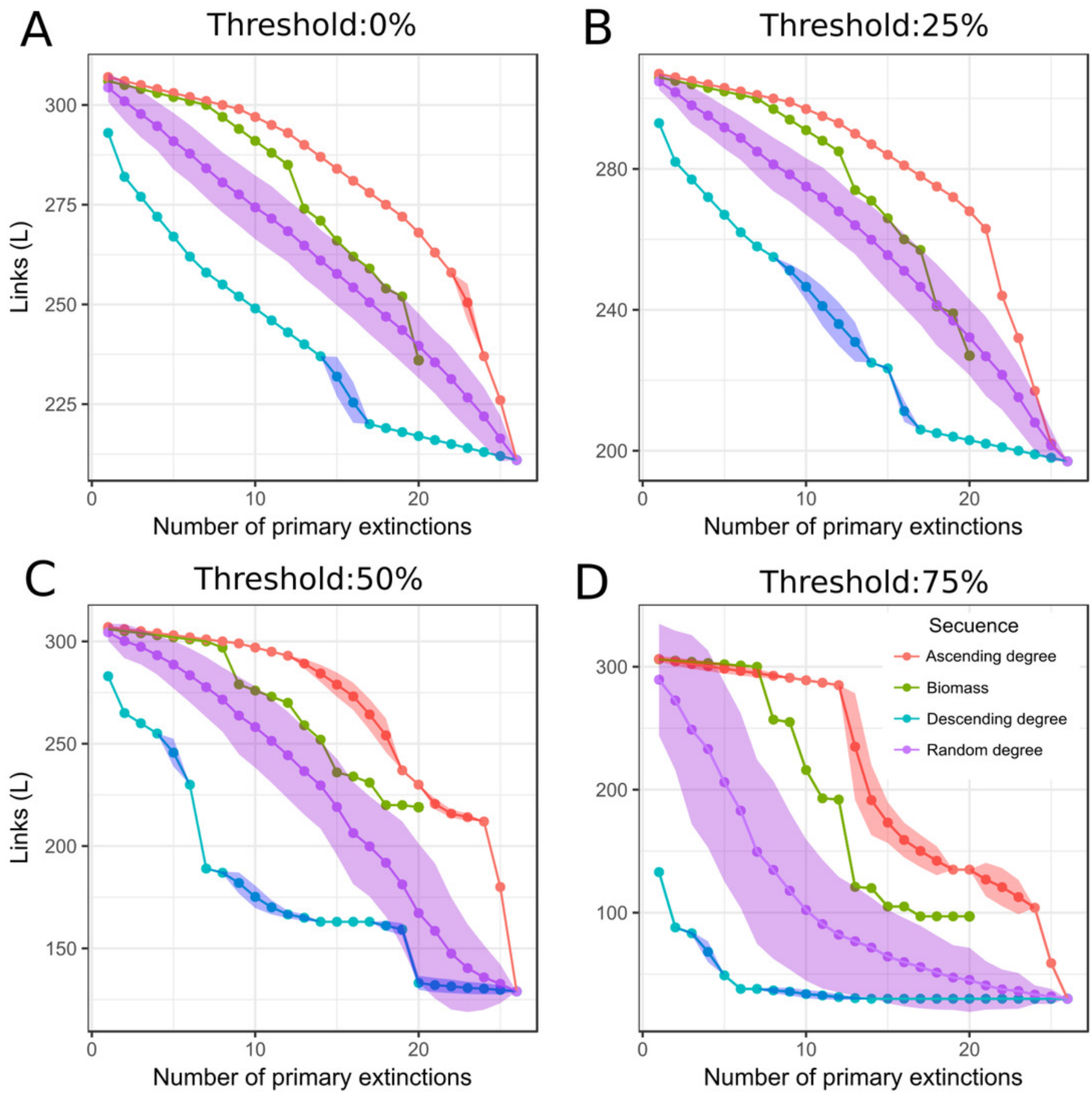


\section{Figure 4}

Connectance response to simulation of species loss

Connectance $(C)$ vs primary extinctions, when macroalgae species and detritus were removed. $C$ was computed after primary and secondary extinctions have taken place. Each box corresponds to a different threshold (v) (A: $0 \%$, B: $25 \%$, C: $50 \%$ and D: $75 \%$ ). Macroalgae loss was done following different sequences of extinctions: red, ascending degree (mean and standard deviation); blue, descending degree (mean and standard deviation); violet, random degree (mean and standard deviation) and green, biomass (ascending order). 

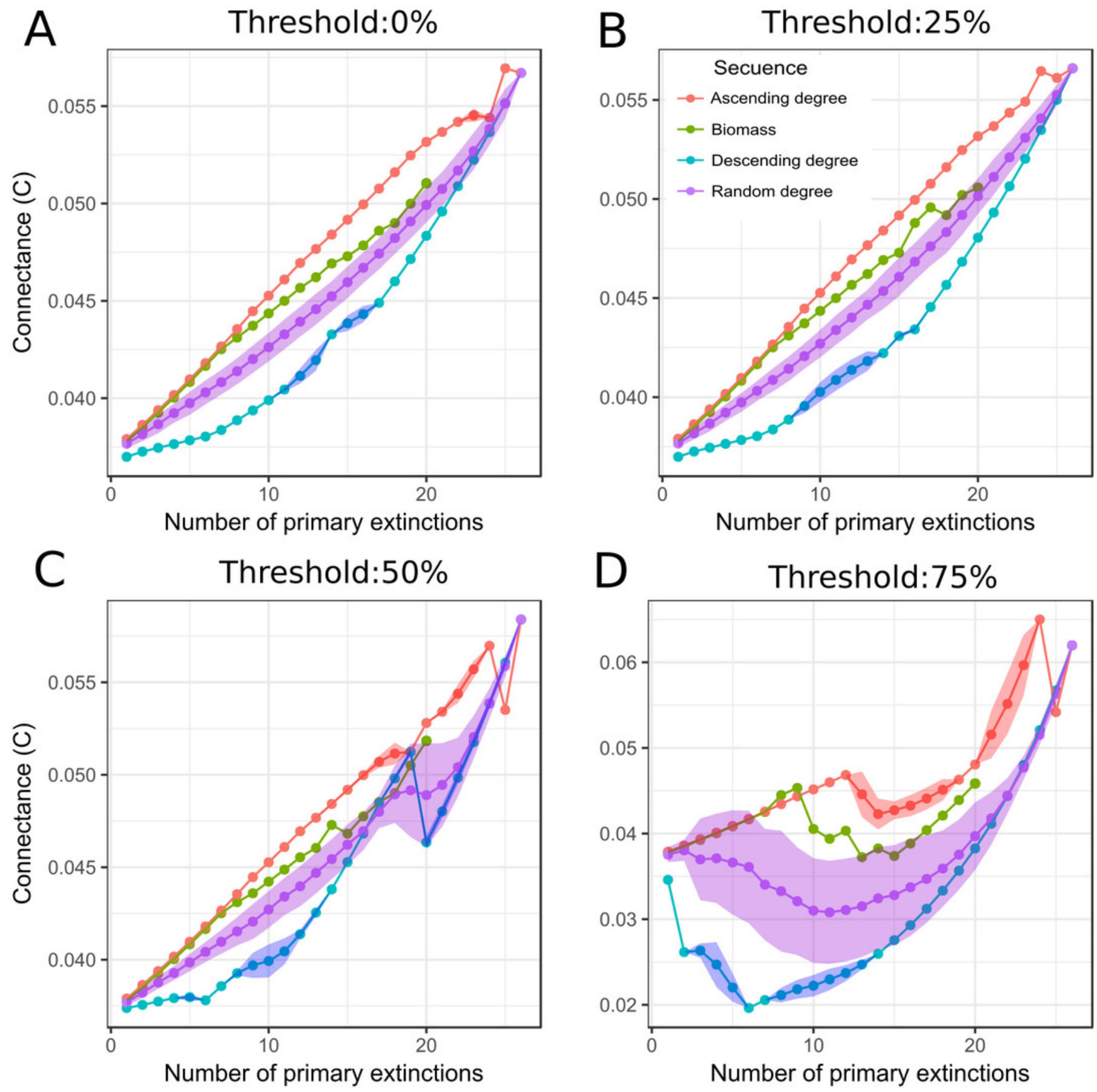


\section{Figure 5}

Secondary extinctions response to simulation of species loss

Secondary extinctions vs primary extinctions, when macroalgae species and detritus were removed. Each box corresponds to a different threshold (v) (A: $0 \%, B: 25 \%, C: 50 \%$ and D: $75 \%$ ). Macroalgae loss was done following different sequences of extinctions: red, ascending degree (mean and standard deviation); blue, descending degree (mean and standard deviation); violet, random degree (mean and standard deviation) and green, biomass (ascending order). 

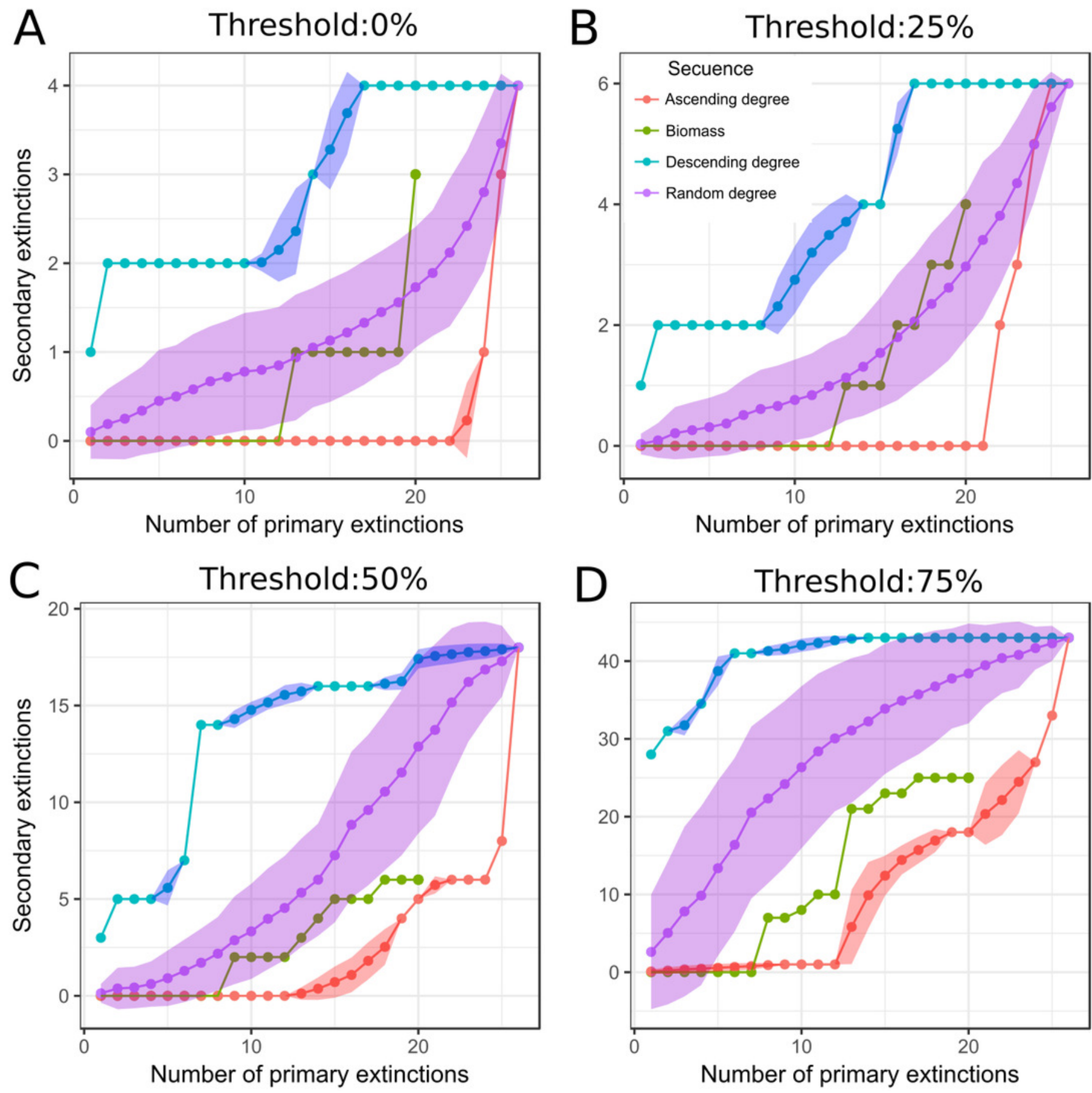
Figure 6

Effect of threshold in secondary extinctions

Secondary extinctions with threshold $(v)$ variations (from $5 \%$ to $95 \%$ by $5 \%$ ) when macroalgae are primary lost (blue: three, brown: five, green: ten, red: fifteen, pink: twenty). Points are means of secondary extinctions when $x$ number of primary extinctions took place at a particular $v$ (by random simulations). Shaded area represents confidence interval of the series.

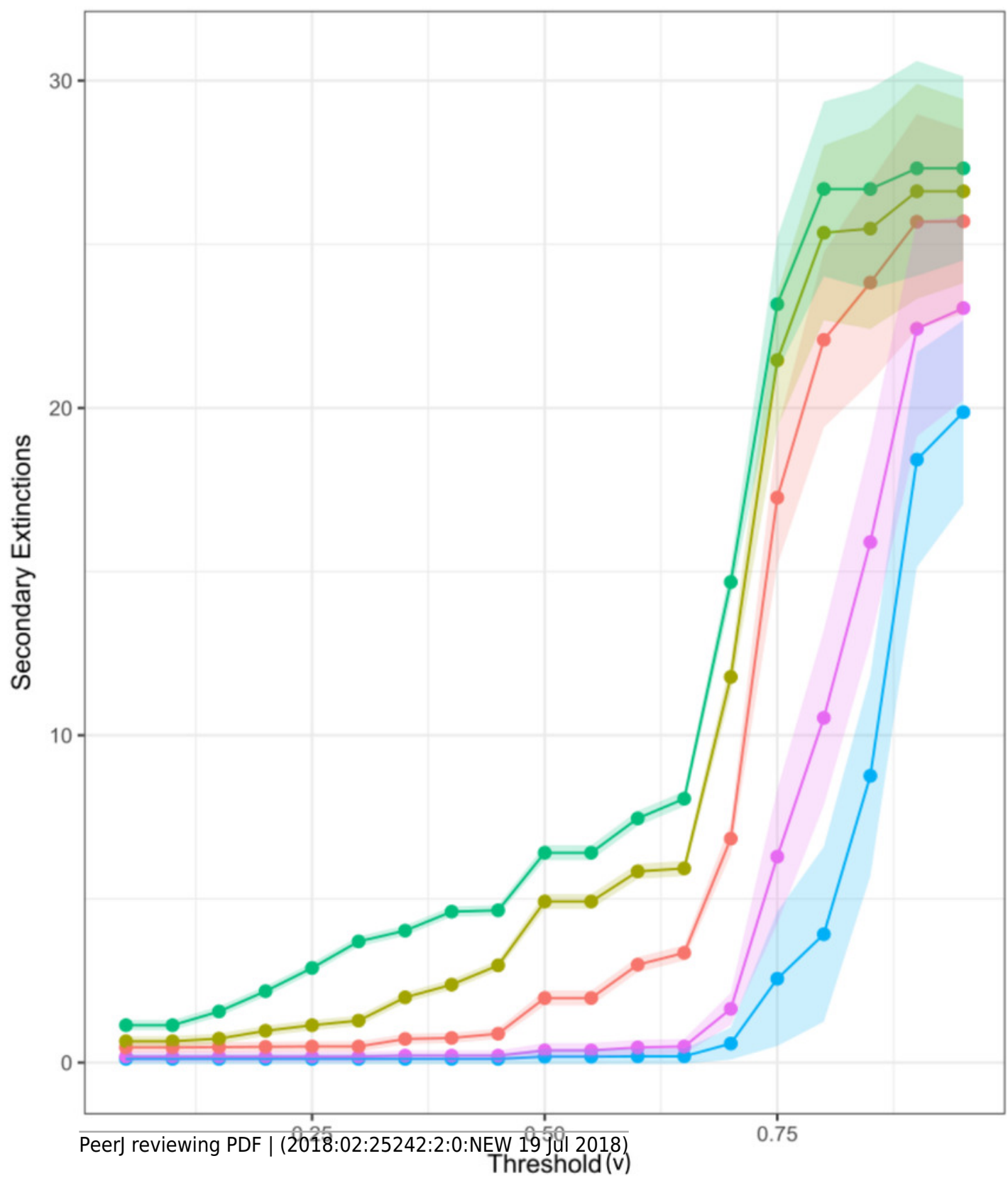

Primary Extinctions

$$
\begin{aligned}
& 3 \text { species } \\
& -5 \text { species } \\
& -10 \text { species } \\
& -15 \text { species } \\
& -20 \text { species }
\end{aligned}
$$

